\title{
双方向クランパーによるレベル設定
}

\author{
非会員 金 端 利 典 (大日本印刷) \\ 正員田口耕造 (福山大学) \\ 正員溝尻勲 (立命館大学)
}

\section{Base Level Estimator Using Bilateral Clamper}

Toshinori Kanahashi, Non-member(Dai Nippon Printing),

Kozo Taguchi, Member(Fukuyama University), Isao Mizoshiri, Member (Ritsumeikan University)

\begin{abstract}
We often encounter with a signal composed of a base level signal slowly varying in time and a relatively fast varying signal of interest, such as electrocardiogram and video signal of cars running on a road. In order to set the base level signal, we usually estimate the base level signal by a lowpass filter using difference of characteristics in frequency domain between these two signals. However, a base level estimator of the linear filter is directly affected by amplitude of the signal of interest.

We propose the new base level signal estimator using a bilateral clamper that consists of two linear filters and a non-linear element, moreover, analyze precisely and give roughly design criteria. This estimator has nice response to the change of the base level signal, and well protects the affection of the signal of interest.

Finally, we demonstrate usefulness of this estimator showing some examples.
\end{abstract}

キーワード : 基準レベル, 線形フィル夕, 非線形演算子, 双方向クランパー

\section{1. まえがき}

時系列信号には，時間的にゆるやかに変動寸る基準レべ ルの信号に比較的早く変動する信号成分が加わっているも のがある、この様な信号の基準レベルを設定することは, 時間的に変動する画像中から移動物体を抽出[1]したり心電 図のベースレベル設定など様々な場面で利用される。しか し基準レベル以外の成分が特別な性質を持たない場合には， その設定は一般に困難である。

現在までに，基準レベル設定の一例として線形フィル夕 在用いる方法が提案されている[2]。この方法は，基準レバ ルはその変動がゆるやかであり，周波数領域では他の信号 成分に比心低域に存在することに着目し, 線形心低域通過 フィルタ (low pass filter)を用いて, 基準レベルの信号を推 定している。低域通過フィルタを用いる力法の利点は, 簡 単なフィルタで推定可能であることから处理が高速である こと, 雑音成分がランダムであっても基準レベルの信号が 推定できることが挙げられる. しかし，基準レベルの信号 スペクトルと他の信号成分の帯域が明確に分離できず，基 準レベル成分以外の影響を受け正確にレベルを設定できな いといった問題がある。それゆえ，荒川らは信号の予測誤 差に着目寸ることにより信号の定常成分と非定常成分を分
離する機能を持った非線形ディジタルフィルタシステム[3][4\} 老提案している。

本論文では，予測つィルタ (prediction filter) を用いず，線 形フィルタ(平滑化フィルタ)に，しきい值によって出力が変 化する非線形演算子を組夕合扣せた双方向クランパーを作 成し，基準レベルの設定を行う.

提案する双方向タランパーは, 非線形演算子の出力が変 化することによって次の 2 通りの出力特性を持つ。一つは, 振幅の小さな変動とみなせる基準レベルの変動には，線形 フィルタと同じ特性となり，その変動に追従する。他の一 つは，振幅の大きな変動とみなせる基準レベル以外の変動 には，非線形演算子で出力を相殺することによって影響を 受けにくい，という特性である。

本論文では，基準レベル設定に用いられる線形フィル夕 と比較しながら，双方向クランパーの検討を行う。また：シ ミュレーション実験と基準レベル設定の一例である時系列 画像からの背景推定実験を行うことによって, 本手法の有 效性を示す。ただし仮定として，推定目的とする基準レ心゙ ルの信号が雑音や基準レベル以外の成分に比べ変動がゆる やかであるものとし，また入力信号は，基準レベルの成分 に比べ基準レベル以外の成分が現れる頻度が少ないものと する。 
以下 2 章では提案する双方向クランパーの各部の性質に つて述心，3章では双方向クランパーの出力老解析によっ て求める．さらに4 章で赛験と検討を行い，5章でまとめ を述べる。

\section{2. 双方向クランパーの構成図}

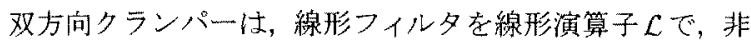

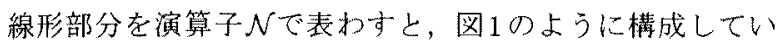
る. 図1において $x(t)$ は入力, $y_{1}(t)$ は 1 目の線形フィル夕 か出力, $y_{2}(t)$ はつ目の線形フィルタの出力, $g(t)$ は提案し た双方向タランパーの出力(Output)である。

双方向クランパーの各部の入出力関倸は式(1)のように な司。

$$
\begin{aligned}
& \left\{\begin{array}{l}
y_{1}(t)=\mathcal{L} x(t) \\
y_{2}(t)=\mathcal{L N}(x(t)-g(t)) \\
g(t)=y_{1}(t)-y_{2}(t)
\end{array}\right. \\
& \mathcal{L} x(t)=\int_{0}^{\infty} x(t-\tau) h(\tau) d \tau
\end{aligned}
$$

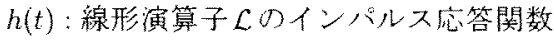

双方向クランパーの出力 $g(t)$ は式(1)より

$$
g(t)=\mathcal{L} x(t)-\mathcal{L N}(x(t)-g(t))
$$

となる。

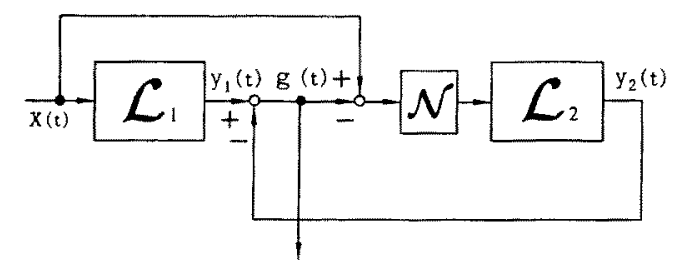

Output

図 1 双方向クランパーの構成図

Fig.1 A schematic diagram of bilateral clamper

\section{3: 双方向クランパーの解析}

$<3 \cdot 1>$ 非線形演算子の性質 非線形演算子 $\mathcal{N}$

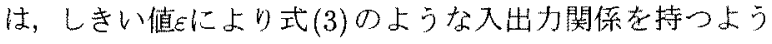
に定める。ここで $f(t)$ はNの力，N $f(t)$ はN

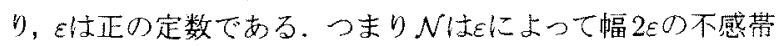
を持つ、図2に非線形演算子 $N$ 闪出力関係を示寸。

$$
\mathcal{N} f(t)=\left\{\begin{array}{cc}
f(t)+\varepsilon, & f(t)<-\varepsilon \\
0, & |f(t)| \leq \varepsilon \\
f(t)-\varepsilon, & f(t)>\varepsilon
\end{array}\right.
$$

ここで解析に便利なように，非線形演算子Nを式(4)で表 される新たな非線形演算子 $\mathcal{N}^{\prime}$ と恒等演算子 1 を用いて

$$
\mathcal{N}=\mathcal{N}^{\prime}+1
$$

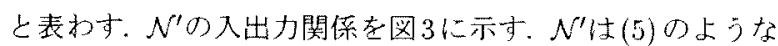
入出力関係在持つ。

$$
\mathcal{N}^{\prime} f(t)=\left\{\begin{array}{cc}
\varepsilon & , \quad f(t)<-\varepsilon \\
-f(t), & |f(t)| \leq \varepsilon \\
-\varepsilon, & f(t)>\varepsilon
\end{array}\right.
$$

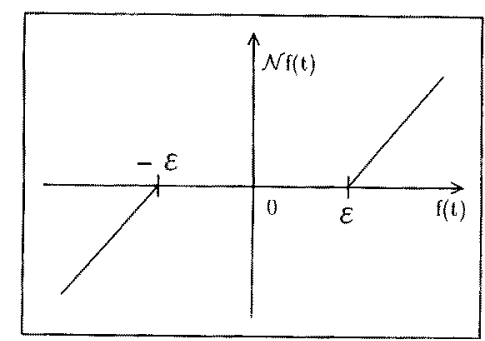

図2 $f(t)$ とN $f(t)$ の関倸

Fig.2 Input-Output relation of $\mathcal{N}$

式(2)から，出力g(t)は的を用いて式(6)の上うになる。

$$
\begin{aligned}
g(t) & =\mathcal{L} x(t)-\mathcal{L}\left(\mathcal{N}^{\prime}+1\right)(x(t)-g(t)) \\
& =\mathcal{L}\left(g(t)-\mathcal{N}^{\prime}(x(t)-g(t))\right)
\end{aligned}
$$

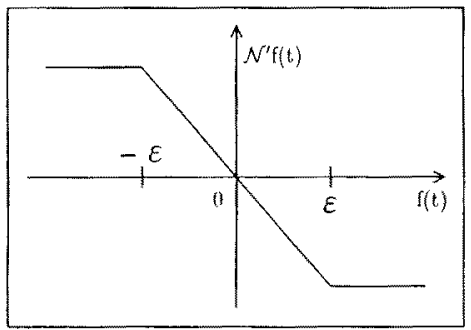

図3 $f(t)\left\llcorner\mathcal{N}^{\prime} f(t)\right.$ O)関保

Fig.3 Input-Output relation of $\mathcal{N}^{\prime}$

$<3 \cdot 2\rangle$ 解析 双方向クランパーは線形演算子 $\mathcal{L}$ 上非線形演算子N (6)で求められる、しかしNは式(3)に示したように入力に よって特性が変化ずるため，No入力について場合わけを 行い $g(t)$ 在求める。

(i) $|x(t)-g(t)| \leq \varepsilon の と き$

$$
\begin{aligned}
\mathcal{N}^{\prime}(x(t)-g(t)) & =-(x(t)-g(t)) \text { から } g(t) \text { は, } \\
g(t) & =\mathcal{L}\left(g(t)-\mathcal{N}^{\prime}((x(t)-g(t)))\right. \\
& =\mathcal{L} x(t) \\
& =y_{1}(t)
\end{aligned}
$$

となる。したがって, 非線形演算子の入力の絶対值 $|x(t)-g(t)|$ がしきい值坝下のとき，双方向クランバーの出力 $g(t)$ は線 形演算子L出力 $y_{1}(t)$ と等しくなる。 
(ii) $|x(t)-g(t)|>\varepsilon$ のき

$$
\begin{aligned}
\mathcal{N}^{\prime}(x(t)-g(t))= \pm \text { から } g(t) \text { は, } \\
g(t)=\mathcal{L}\left(g(t)-\mathcal{N}^{\prime}(x(t)-g(t))\right) \\
\quad= \begin{cases}\mathcal{L} g(t)+\mathcal{L} \varepsilon, & x(t)-g(t)>\varepsilon \\
\mathcal{L} g(t)-\mathcal{L} \varepsilon, & x(t)-g(t)<-\varepsilon\end{cases}
\end{aligned}
$$

上り,

$$
g(t)= \pm(1-\mathcal{L})^{-1} \mathcal{L} \varepsilon
$$

となる.ここで式(9)を演算子のNeumann展開を用いて表 せば

$$
g(t)= \pm\left(\mathcal{L}+\mathcal{L}^{2}+\mathcal{L}^{3}+\cdots\right) \varepsilon
$$

である。

次に，双方向クランパーの一部分である線形演算子 $\mathcal{L}$ と して, 式(11)で表される一次の伝達関数 $H(s)$ を用いる.

$$
H(s)=\frac{1}{\frac{1}{\alpha} s+1}
$$

そのとき式(9)は，

$$
G(s)= \pm \frac{\varepsilon \alpha}{s^{2}}
$$

となるよって $g(t)$ は，式(12)の逆ラプラス変換から

$$
g(t)= \pm \varepsilon \alpha t
$$

となる.すなわち，非線形演算子の入力の絶対値 $|x(t)-g(t)|$

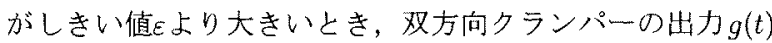
は, 入力 $x(t)$ に関係なくパラメー夕 $\alpha$ とに積を係数に持つ 時間 $t$ の一次関数になる.

提案する双方向クランパーは, 振幅の小さな変動とみな せる基準レベルの変動には，平滑化フィルタと同じ特性と なり，その変動に追従し，振幅の大きな変動とみなせる基 準レベル以外の変動には, 非線形演算子で出力を相殺する ことによって背景の緩やかな変動のみの抽出が可能である. ただし，現実には標準 $z$ 変換を用いて $s$ 領域におけるアナ゙ グフィルタの伝達関数 $H(s)$ 在 $z$ 領域一変換し離散伝達関数 $H(z)$ を求め, 非線形ディジタルフィルタにより双方向クラ ンパーを構成している。

\section{4. 実験結果}

〈4·1> シミュレーション実験＼cjkstart計算機シミュ レーションによってディジタルフィルタにより構成している 双方向クランパーの出力 $g(t)$ と, 線形演算子 $\mathcal{L}$ の出力 $y_{1}(t)$ を求めた結果を示し，比較抢上び検討を行う。ただし，全て のシミュレーション実験で, パラメータは $\alpha=0.05, \varepsilon=5$ と設定している.

\section{(i) ステップを入力した結果}

図4は入力を $x(t)=3$ ，および $x(t)=25$ のステップとした ときの, 双方向クランパーの出力 $g(t)$ と線形演算子 $\mathcal{L}$ の出力 $y_{1}(t)$ である. 図の実線はしきい值 $\varepsilon(=5)$ 以下の $x(t)=3$ のス テップを入力したときの出力，破線は $\varepsilon$ よ大きい $x(t)=25$ のステップを入力したときの出力である．また，黒点は出 力 $g(t)$, 黑三角は出力 $y_{1}(t)$ である.

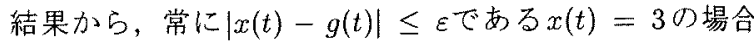
は, $g(t)=y_{1}(t)$ となっており，これは<3.2>(i)の解析結 果である式(7)に等しい.一方， $x(t)=25$ のステップを入力 した場合， $g(t)$ は $y_{1}(t)$ に比べ出力が遅くまた出力が直線と なっている、これはく $3.2>$ (ii) の解析結果である式(13)に 等しい，ただし $x(t)=25$ のとき, $g(t) か ゙ ~ t=85$ 付近で值線 から曲線に変化しているのは, ここで $|x(t)-g(t)|>\varepsilon か ら$

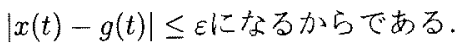

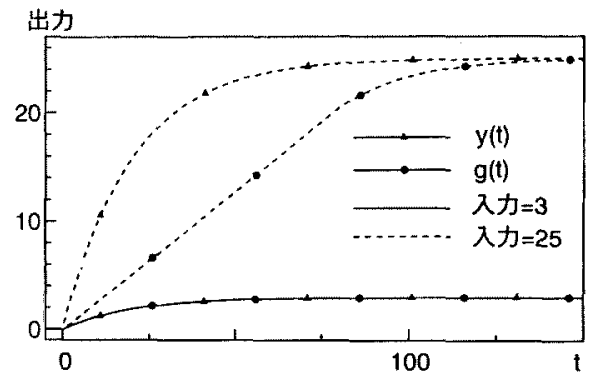

図4 $x(t)=3$ および 25 のスップのときの出力の比較

Fig.4 Comparison of responses between bilateral clamper and liner filter $\mathcal{L}$ as $x(t)=3,25$

(ii) パルス信号を加えた結果

図 5 は基準レベルの信号にパルス成分を加えたものを入 力 $x(t)$ とし, 双方向クランパーの出力 $g(t)$, 線形演算子 $\mathcal{L} O$ 出力 $y_{1}(t)$ を求めた結果である、ただし $x(t)$ は次式で表わさ れるもので, $x_{b}(t)$ は基準レベル成分, $x_{p}(t)$ はパルス成分で ある。

$$
x(t)=x_{b}(t)+x_{p}(t)
$$

図5において，Aはパルスの振幅，T帖はパルス幅，Tは入 力 $x(t)$ の周期, $E_{\max }$ は出力の最大誤差つまり基準レベルか らのずれの最大值, また, 細線は入力 $x(t)$, 破楾は線形演算 子 $\mathcal{L}$ の出力 $y_{1}(t)$, 太線は双方向クランパーの出力 $g(t)$ であ

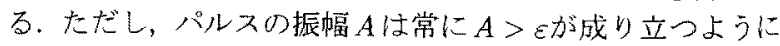
する.

図6は周期 $T=100$ ，基準レベル $x_{b}(t)=0$ 信号に，幅 $T_{p}=40$, 振幅 $A$ がしきい值とより大きい 6 から 100 までの式 (14) で表される入力 $x(t)$ を加え, 出力 $g(t), y_{1}(t)$ の最大誤 差 $E_{\max }$ を求めたものである.ただし，この実験においては $|x(t)-g(t)|>\varepsilon$ となるようにパルス幅 $T_{p}$ を設定している. 


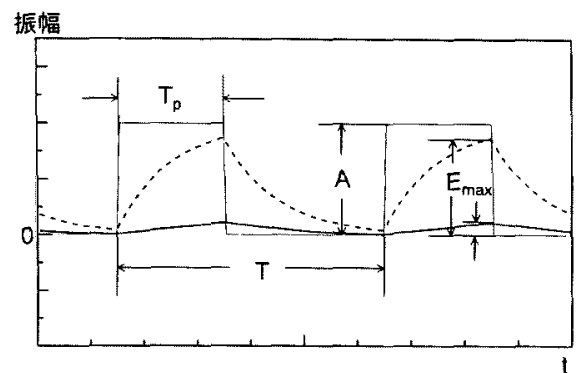

図5 基準レベルにパルスを加えたときの入出力

Fig.5 Input-Output relation as $x_{b}(t)=0, x_{p}(t)=A$

出力の最大誤差 $E_{\text {max }}$

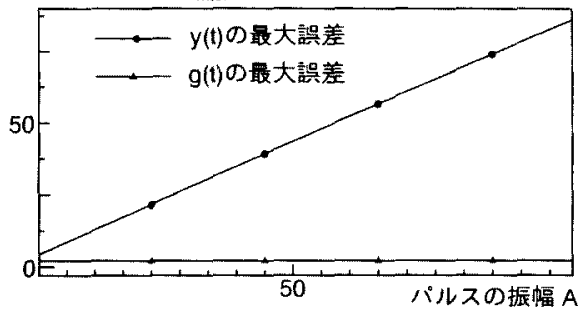

図6 パルスの振幅と $y_{1}(t), g(t)$ の最大誤差 $E_{\max }$ の関係 Fig.6 Relation between $E_{\max }$ and magnitude of pulse as $T=100, x_{b}(t)=0, T_{p}=40$

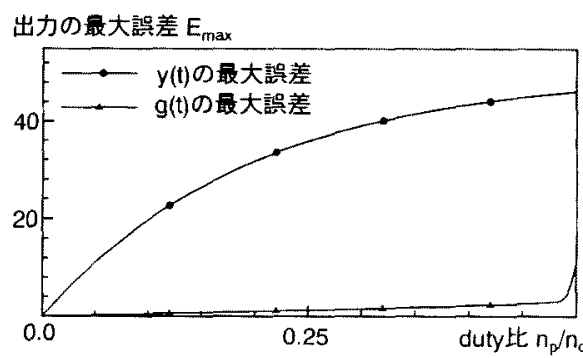

図7 $x(t)$ の duty比と $y_{1}(t), g(t)$ の最大誤差 $E_{\max }$ の関倸

Fig.7 Relation between $E_{\max }$ and duty factor as $T=100, x_{b}(t)=0, A=40$

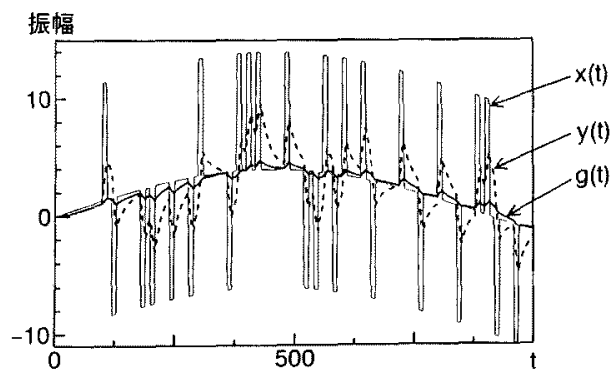

図 8 基準レベルを変動させたときの出力 $g(t)$ と $y_{1}(t)$ Fig.8 Simulated bihaviors of $y_{1}(t), g(t)$
図6に㧈いて横軸はパルスの振幅 $A$ ，縌軸は出力の最大 誤差 $E_{\max }$ である。，実験結果から，双方向クランパーの出力 $g(t)$ の最大誤差 $E_{\text {max }}$ は，パルスの振幅 $A$ に上らず一定であ る。一方, 線形フィルタの出力 $y_{1}(t)$ の最大誤差は, パルス の振幅 $A$ に比例し誤差が増大している，つまりAが大きい ほど出力 $y_{1}(t)$ に影響を受ける。これらは，式(13)に示した 解析結果に一致寸る。したがって，g(t)は基準レベル以外の 成分であるパルスの振幅が增大寸るほど， $y_{1}(t)$ に比べ良好 に基潐レベルを推定できることがわかる。

図7は周期 $T=100$ ，基準レベル $x_{b}(t)=0$ の信号に，振幅 $A=40$, dutu比 $=n_{p} / n_{c}$ が 0 から 0.5 まで変化させた式 $(14)$ で表される入力 $x(t)$ を加え, $g(t), y_{1}(t)$ の最大䛊差 $E_{\max }$ を 求めたものである。図の横軸は $x(t)$ の duty 比, 綎軸は出力 の最大誤差 $E_{\text {max }}$ である

結果から, duty比が大きくなるに従い, 線形フィルタの 最大誤差 $E_{\text {max }}$ は增大し，また双方向クランパーの出力 $g(t)$ の最大誤差 $E_{\max }$ も增加する。これはく3.2>(ii) の解析結果 である式(13)に一致する.duty比が大きくなると $g(t), y(t)$ ともに誤差が大きくなるが, duty比によらず, $g(t)$ の最大誤 差 $E_{\max }$ はy $(t)_{1}$ の最大誤差 $E_{\max }$ に比べ十分小さい.このこ とから，双方向クランパーの方が良好に基淮レベルを設定 できていることが解る.ただし， $g(t)$ の $E_{\text {max }}$ がduty 比 $=0.5$ 付近で急激に増大しているのは, duty比>0.5ではパルス波 頭が基準レベルとみなされ $g(t)$ が方形パルス波頭を推定す るからである。また本論文では，入力信号は基準しベルの 成分に比心゙基準レベル以外の成分が現れる頻度は少ないと 仮定しているので，duty比が0.5以上のものは考えない。

図8 は基準レベルをゆるやかに正弦波状に変動させ，二れ にパルスを加えた信号を入力 $x(t)$ とし，出力 $g(t), y_{1}(t)$ を 求めた結果である。パルスの振幅は $A=10$, 幅は $n_{p}=10$, duty比は0.5以下でランダムにしている。

この結果から，線形フィル夕の出力 $y_{1}(t)$ は基準レベルの ゆるやかな変動には追従しているが，パルスの影響を受け， 正確な基準レベル推定は行われていない。これに対して双 方向クランパーの出力 $g(t)$ は，パルスの影響起よんど受 けず基準レベルの推定が行われている，つまり双方向クラ ンパーはゆるやかな変動に迫従し，一方でEより大きい変動 の影響は梳とんど受けない。これより，本手法は線形演算 子に比べ基準レベル設定に有効であることが解る.

$\langle 4 \cdot 2\rangle$ 実信号に対する適用例 双方向クラン パーの有效性を示す実例として, 背景の輝度信号を基淮レ ベルとする実験を行った

図9は入力信号を抽出した画像の1フレームであり，車の 走行する道路を撮影したものである，また，入力信号は撮 影した画像の×印で示した所の輝度時系列信号 $x(t)$ である。

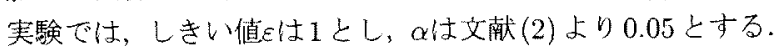
入力信号において，基準レベルである背景成分は輝度值が 90 付近で変化している部分であり，細かく変化している部 分は力メラの振動などによる画像の雑音成分である。また，

電学論C, 117 巻 7 号, 平成 9 年 
インパルス状に振幅が大きく変化している部分は車両の通 過を表している。

図10から, 破線で示される線形フィルタの出力 $y_{1}(t)$ は, 車両が存在しない $t=25$ 付近では良好に背景を推定してい るが, 車両が通過する時点では背景推定に大きな誤差が生 じている.これは線形フィルタが, 基準レベル以外の成分 の振幅の大きさに比例し誤差が生じるからである.さらに この誤差が, 背景部分における推定にも影響をおよぼし, $t=75$ 付近では大きな誤差を生じているのが解る.

これに対し双方向クランパーの出力 $g(t)$ は, 車両部分に おいても背景部分においても良好に背景推定を行っている. また車両が通過する時点においても，良好に背景推定を行っ ている.この結果から, 基準レベル設定に本手法が有効で あることがわかる。

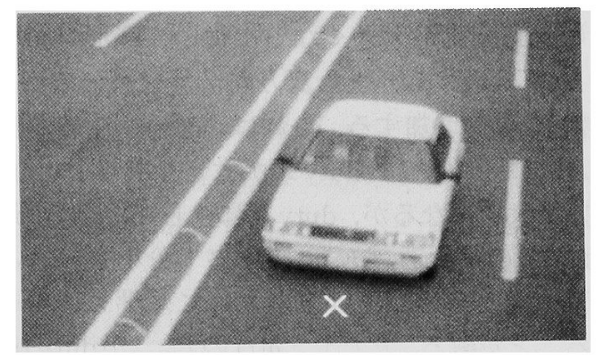

図9画像における入力信号を抽出した位置

Fig.9 Time series signal acqusition point

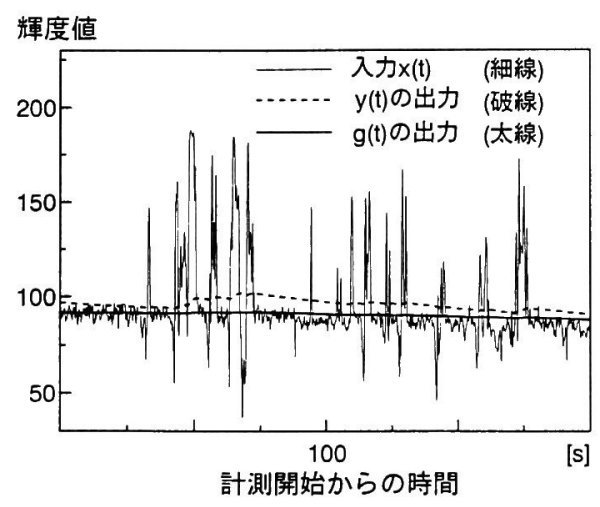

図10 画像の時系列信号の実測值と推定值

Fig.10 Comparison with two estimated base levels

\section{5. むすぴ}

雑音や突発的な成分を含んだ信号から，基淮レベル設定 を行うために双方向クランパーを用いる方法を提案した。 双方向クランパーは, 一次系の簡単な線形フィルタに非線 形素子を組み合わせたもので, 特性が非線形素子の入力に 伴って変わることから場合わけを行い解析をし, その出力 を求めた。 また，シミュレーション実験を行い双方向クラ ンパーの出力と今回用いた線形フィルタの出力の比較する ことによって有効性を示し, さらに双方向クランパーの適
応例として，環境変動による輝度変化や車両による鿵蔽な どによって変化する画像中の背景輝度を推定し, 本方法の 有効性を示した.

(平成 8 年 3 月 11 日受付, 平成 8 年 10 月 1 日再受付)

\section{文献}

[1] 金端, 田口, 溝尻 : 双方向クランパーによるレベル設 定, 平成 7 年電気関倸学会関西支部連合大会講演論文 集, pp.G26(1995)

[2] 田口, 金端, 中西, 溝尻: ディジタル動画像処理によ る移動物体抽出, 電気学会論文誌, Vol.114-c, No11, pp.1148-1153(1994)

[3] K.Arakawa,et.al." Separation of a Nonstationary Component from the EEG by a Nonlinear Digital Filter",IEEE Trans. Biomed.Eng.,BME33-7, pp.724726(1986)

[4] 荒川, 原島, 大野, 毛利: 呼吸音における crackle分離 抽出を目的としたディジタルフィルタシステム, 医用 電子と生体工学, 27-2,pp112-116(1989)

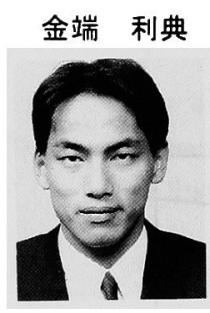

田口 耕造

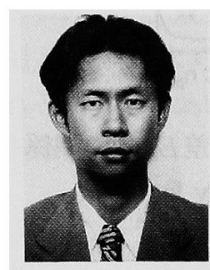

溝尻 勲

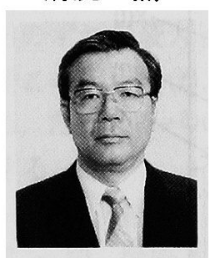

(非会員) 1969 年11月 21 日生まれ。 1996 年 3 月立命館大学大学院理工学研 究科修士課程電気工学専攻修了. 同年 4 月大日本印刷株式会社入社. 在学中, 非線形フィルタ，動画像処理に関する 研究に従事.

(正員) 1968 年 12 月 18 日生まれ. 1996 年 3 月立命館大学大学院理工学研究科 博士課程電気工学専攻修了. 博士 (工 学). 同年 4 月福山大学工学部電子電気 工学科助手. 画像計測, 信号処理, 光 トラッピング, 光機能回路に関する研 究に従事. 電気学会, 応用物理学会な どの会員

(正員) 1941 年 10 月 6 日生まれ. 昭和 40 年大阪府立大学工学部電子卒業. 同年 三洋電機 (株) 入社. 47 年大阪府立大学 大学院博士課程修了. のち, 福井大学 講師, 助教授を経て, 現在, 立命館大 学理工学部教授. 電子回路, 画像処理, 生体システムに関する研究に従事. 工 学博士. 電気情報通信学会, ME学会, IEEE 会員. 